\title{
High-Speed Imaging of Turbulent Nonpremixed Syngas Flames at Elevated Pressures
}

\author{
Wesley R. Boyette • Thibault F. \\ Guiberti • Ayman M. Elbaz • William \\ L. Roberts
}

Received: date / Accepted: date

\begin{abstract}
To address the paucity of experimental data on well-documented turbulent jet flames at elevated pressures, a high pressure rig has been used to explore turbulent nonpremixed syngas flames at elevated pressures and very high Reynolds numbers. Composite images of the flames reveal small changes in flame length that are in agreement with previous empirical correlations. $\mathrm{OH}-$ PLIF images are used to visualize the flame structure, revealing an $\mathrm{OH}$ layer that gets progressively thinner as pressure increases. A corrugation factor is defined and used to show that flame front corrugation is influenced by increases in Reynolds number and axial distance from the nozzle, but not pressure.
\end{abstract}

Keywords High pressure $\cdot$ Turbulent nonpremixed flames · Syngas

\section{Introduction}

Modern engineering of practical combustion devices is increasingly reliant on design evaluation by high-fidelity numerical simulations of turbulent reacting flows. Combustor design was originally a "black art" which relied on experience and judgement; it was aided by the rise of the digital computer and mathematical models of turbulent flow [1]. Currently, the majority of modeling strategies employ Reynolds-averaged Navier-Stokes (RANS) approaches. However, RANS models are typically developed for mean stationary flow, making them ill-suited for increasingly complex combustor flows that include unsteadiness and inhomogeneities [2]. With significant advances in computing power in recent decades, alternative strategies, particularly large eddy simulation (LES), offer a way to study coupled mixing and combustion processes with greater

W. Boyette

King Abdullah University of Science and Technology (KAUST), CCRC, Thuwal, 23955-6900 Saudi Arabia

E-mail: wesley.boyette@kaust.edu.sa 
accuracy than RANS [3]. Direct numerical simulation continues to be far too computationally expensive for combustor design.

In LES, the large-scale coherent eddy structures, which comprise a major part of the Reynolds stresses and are geometrically dependent, are fully resolved, offering great advantages in comparison with RANS. These fullyresolved features determine entrainment rates into the mixing layers, thereby controlling the composition of resulting reactive gas pockets [4]. The smallest scales remain unresolved, requiring subgrid-scale (SGS) models. The mixing and dissipation processes at these scales are thought to be more universal in character, reducing the need to tune model constants [3]. Nonetheless, LES faces the same closure problem as RANS because the coupling between reaction and molecular mixing still occurs at the smallest scales [5]. In fact, many of the SGS models for LES have been used previously in RANS calculations $[6]$.

Because LES requires SGS closure schemes that must model the temporal and spatial characteristics of a flow system accurately, the models must be validated with appropriate test cases before being implemented in simulations of practical combustion devices.

The search for and identification of turbulent flame test cases suitable for model validation began many years ago. In 1983, a study conducted by the Air Force Office of Scientific Research began a program to establish a welldocumented database in turbulent reacting flows. A report by Strahle (1986) [7] summarized the results, concluding that no databases were available that could meet all of the established criteria: measurements of a vector, scalar, and some turbulence quality at many streamwise and cross-stream locations, high measurement accuracy or at least an accuracy estimate, measurement of initial conditions, fully turbulent flow everywhere in the computational domain, and several others. Along with this report, more detailed papers were delivered summarizing existing databases, including fast-reaction (where characteristic transport times are large in comparison to characteristic times of reactions) nonpremixed flames [8], and slow-reaction nonpremixed flames [9]. Facilitated by advances in laser diagnostics [10] as well as turbulence modeling and computer technology [11], the need for a better set of flame databases led to the establishment of the International Workshop on Measurement and Computation of Turbulent Nonpremixed Flames (TNF Workshop) in 1996 [12].

The TNF Workshop has strived to establish a database of flames that are relatively easy to create in the laboratory and to model, but that retain the complex physics of reacting flows often encountered in real work-producing devices. Experimental data can then be compared directly with models, without the need for oversimplified geometries or unwarranted assumptions. The database covers a range of chemical complexity including $\mathrm{H}_{2}$ and $\mathrm{H}_{2} / \mathrm{He}$ [13], $\mathrm{CO} / \mathrm{H}_{2} / \mathrm{N}_{2}$ [14], $\mathrm{CH}_{4} / \mathrm{H}_{2} / \mathrm{N}_{2}$ [15], and DME [16]. The database also ranges in geometric complexity from simple or piloted jet flames [17] to bluff body burners [18] and, more recently, to turbulent stratified flames [19,20] and a piloted jet flame with inhomogeneous inlets [21]. 
There have only been a few examples of experiments on turbulent diffusion flames at elevated pressures [22-25], and as of yet, all of the TNF Workshop flames have been operated at atmospheric pressure. As numerical models are being developed to simulate devices working at high pressures, it is imperative that such models be validated first with simple flames at relevant operating conditions. Furthermore, by exploring such flames at elevated pressures, experimentalists gain the ability to operate at Reynolds numbers that are otherwise unachievable (aside from the piloted hydrogen diffusion flames in [26]) due to flame blowoff, but highly desirable for model validation [27].

In this study, a new high-pressure rig at KAUST is used to explore an existing, atmospheric-pressure flame in the TNF database at elevated pressure and very high Reynolds numbers. The simple jet flame composed of syngas [14] was chosen due to the ease of burner construction and the fuel composition, which is moderately more complex than a hydrogen flame, but resists sooting better than hydrocarbon mixtures. As this study is intended to serve as a proof of concept of the high-pressure rig and an introduction to this family of flames at elevated pressures, the diagnostics employed are relatively simple. A digital single-lens reflex (DSLR) camera is used to identify the contours of the visible flames and measure the flame length. Planar laser-induced fluorescence of hyroxyl radicals (OH-PLIF) is used to characterize the flame structure as the Reynolds number and/or pressure are increased.

The study of flame length (also referred to as flame height) in turbulent jet flames and the formulation of empirical flame-length equations has a long history. One of the earliest known examples of a rigorous study of turbulent jet diffusion flames is given by Hawthorne et al., in which they obtained a relationship between the visible flame length and properties of the mixture that is independent of the fuel flow rate, provided the jet is turbulent [28]. Becker and Liang extended such studies to cover the range of operation from forced convection to natural convection while offering updated flame-length correlations [29], and Kalghatgi found that the non-dimensional groupings suggested by that study ( $\psi$, a function of the fuel, burner diameter, and flame length, and $\xi_{L}$, the Richardson number) were appropriate for collapsing his flame length results onto a single curve [30]. Delichatsios used dimensional analysis to correlate entrainment with flame height data and derived expressions to describe global-flow characteristics for both buoyancy- and momentum-dominant cases [31]. According to that analysis, flame lengths may be converted to nondimensional flame lengths and plotted versus the Froude number of the flame. The flame Froude number $\left(\mathrm{Fr}_{f}\right)$ is a non-dimensional number relating the flow inertia to the buoyancy forces and is defined as

$$
\operatorname{Fr}_{f}^{2}=\frac{U_{j}^{2}}{\frac{\Delta T_{f a}}{T_{0}}(S+1)^{3} g D \sqrt{\rho_{s} / \rho_{0}}}
$$

where $\overline{\Delta T_{f a}}$ is a modified mean flame temperature, approximated in this analysis by the difference between the adiabatic flame temperature and the ambient 
air temperature. $S$ is the air-to-fuel mass stoichiometric ratio, $g$ is the gravitational acceleration, $\rho_{s}$ is the fuel density at the nozzle, and $T_{0}$ and $\rho_{0}$ are the ambient air temperature and density, respectively. The flame length $\left(L_{f}\right)$ is converted to a non-dimensional flame length $\left(L^{*}\right)$ as follows:

$$
L^{*}=\frac{L_{f}}{(S+1) D \sqrt{\rho_{s} / \rho_{0}}} .
$$

A empirical correlation equation for the data was found to be:

$$
\frac{L_{f}}{(S+1) D \sqrt{\rho_{s} / \rho_{0}}}=\frac{13.5 \mathrm{Fr}_{f}^{2 / 5}}{\left(1+0.07 \mathrm{Fr}_{f}^{2}\right)^{1 / 5}} .
$$

The transition from buoyant to momentum jet flames occurs for $3<\operatorname{Fr}_{f}$ $<5$ and flame length is approximately constant for $\operatorname{Fr}_{f}>5$. The lengths of a number of syngas flames in the buoyancy-momentum transition regime were measured by Hwang et al., and good agreement was found with the Delichatsios correlation if the coefficient in Eq. (3) was changed from 13.5 to 11.3 , the justification being a discrepancy in the method of flame length measurement [32]. Hu et al. found that this correlation worked well for flames in a reduced pressure atmosphere, provided that a correction factor of $\alpha_{T}=0.8$ was introduced to account for observed reduced entrainment and increased turbulent fluctuations in the low pressure cases [33]. The present work seeks to address the question of how well the Delichatsios correlation applies to jet flames at elevated pressures.

Planar laser-induced fluorescence (PLIF) of the $\mathrm{OH}$ radical has long been a favorite tool for obtaining qualitative information about the flame structure of turbulent diffusion flames. Seitzman et al. used OH-PLIF to image the structure of turbulent hydrogen nonpremixed jet flames up to $\operatorname{Re}=50,000$ [34]. In an extension of this study, Clemens et al. used OH-PLIF on piloted $\mathrm{H}_{2} / \mathrm{Ar}$ jet diffusion flames with Reynolds numbers ranging from 30,000 to $150,000[26]$. In both cases, the $\mathrm{OH}$ zones appear as thin filaments connected by diffuse regions when the Reynolds number is low, but as the turbulence intensity increases, the $\mathrm{OH}$ zones become more diffuse and highly corrugated on a small scale.

While $\mathrm{OH}$ is not an ideal marker of the flame front in hydrogen diffusion flames, other markers are not commonly used. In hydrocarbon flames, however, other intermediate species may be excited by PLIF, separately or simultaneously, to identify the flame front. Combined $\mathrm{CH} / \mathrm{OH}-\mathrm{PLIF}$ experiments have shown that the reaction zone (marked by $\mathrm{CH}$ ) is limited to a thin region on the fuel side of the $\mathrm{OH}$ layer, whereas the $\mathrm{OH}$ layer itself marks the somewhat thicker radical recombination zone on the lean (air) side of the flame [35]. The overlap of $\mathrm{OH}$ and $\mathrm{CH}_{2} \mathrm{O}$ is also commonly used as a marker for the flame front [36]. A DNS study suggested that the product of $\mathrm{CH}_{2} \mathrm{O}$ and $\mathrm{OH}$ concentrations provided a good reconstruction of the heat release rate in turbulent syngas flames, however, they found that $\mathrm{CH}_{2} \mathrm{O}$ is a very minor species [37]. Laminar flame simulations in Chemkin indicate that $\mathrm{CH}_{2} \mathrm{O}$ concentrations for 


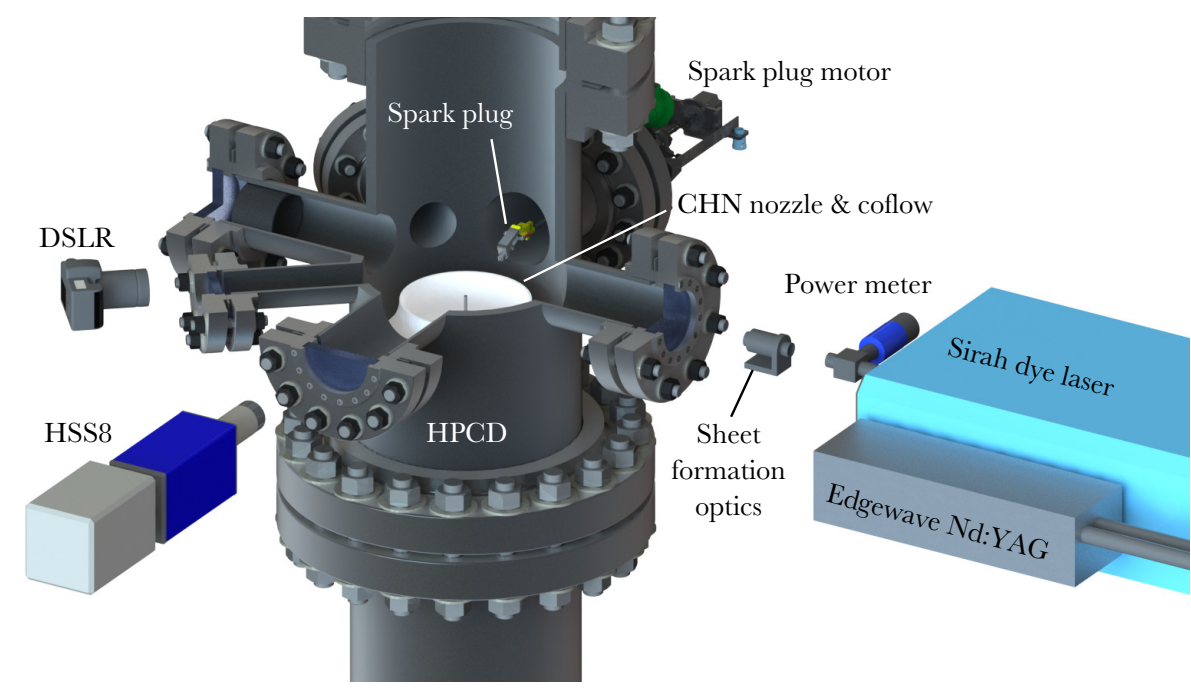

Fig. 1 View of the CHN burner and coflow nozzle inside the HPCD with the diagnostics setup for DSLR camera imaging and high-speed OH-PLIF.

the proposed syngas flame composition are essentially undetectable. With the tools currently available, $\mathrm{OH}$ is the only viable marker for the flame front, and the structure of the flame can be approximated by focusing on the rich side contour of the $\mathrm{OH}$ layer.

\section{Experiment}

The high pressure combustion duct (HPCD) at KAUST is used to perform the experiments. This is a vertically-oriented, $8-\mathrm{m}$ tall, 400-mm inner diameter rig designed especially for operating long turbulent diffusion flames at pressures up to 40 bar. Burners are placed inside the duct from below. The optical section of the HPCD, shown in Fig. 1, features six UV fused silica or BK7 windows (up to $150 \mathrm{~mm}$ diameter), making it possible to perform advanced optical diagnostics, including sterescopic PIV. Burners sit atop a vertical translation stage capable of sub-millimeter movement over a range of $1500 \mathrm{~mm}$, allowing examination of flames from base to tip. The top section of the duct is outfitted with a large back pressure regulator, which allows fine pressure adjustments over a wide range of mass flow rates. For the current study, a spark plug is used for flame ignition. The spark plug is situated on a rod, which passes through the back flange, and is pushed back and forth by a motor outside of the duct, allowing the igniter to be recessed into the back arm of the HPCD once the flame is present. More details may be found in [38]. 
Table 1 Bulk flow parameters for the CHN flames; $p$ is operating pressure, Re is Reynolds number based on the jet diameter $(D=4.6 \mathrm{~mm}), U_{j}$ is the bulk jet velocity, $P$ is the thermal power, and $U_{c f}$ is the bulk coflow velocity.

\begin{tabular}{|ccccccc|}
\hline Series & Designation & $\begin{array}{c}p \\
(\mathrm{bar})\end{array}$ & Re & $\begin{array}{c}U_{j} \\
(\mathrm{~m} / \mathrm{s})\end{array}$ & $\begin{array}{c}P \\
(\mathrm{~kW})\end{array}$ & $\begin{array}{c}U_{c f} \\
(\mathrm{~m} / \mathrm{s})\end{array}$ \\
\hline Baseline & CHN 01-01 & 1.0 & 16,700 & 77.3 & 9.75 & 0.70 \\
\hline \multirow{5}{*}{ Constant Re } & CHN 02-01 & 2.0 & 16,700 & 38.7 & 9.75 & 0.35 \\
& CHN 03-01 & 3.0 & 16,700 & 25.8 & 9.75 & 0.23 \\
& CHN 04-01 & 4.0 & 16,700 & 19.3 & 9.75 & 0.18 \\
& CHN 05-01 & 5.0 & 16,700 & 15.5 & 9.75 & 0.14 \\
\hline \multirow{5}{*}{ Constant $U_{j}$} & CHN 02-02 & 2.0 & 33,400 & 77.3 & 19.5 & 0.70 \\
& CHN 03-03 & 3.0 & 50,100 & 77.3 & 29.3 & 0.70 \\
& CHN 04-04 & 4.0 & 66,800 & 77.3 & 39.0 & 0.70 \\
& CHN 05-05 & 5.0 & 83,500 & 77.3 & 48.8 & 0.70 \\
\hline
\end{tabular}

\subsection{Flame conditions}

The turbulent flames have a geometry identical to the $\mathrm{CO} / \mathrm{H}_{2} / \mathrm{N}_{2}$ flame A (chnA) studied at Sandia and ETH-Zurich as part of the TNF Workshop [14, 39]. The nozzle is constructed from $1 / 4$-inch precision stainless steel tubing with a squared off exit. The nozzle inner diameter is $D=4.6 \mathrm{~mm}$ and the total length is $572 \mathrm{~mm}$. For all conditions, the fuel composition is $40 \% \mathrm{CO}$, $30 \% \mathrm{H}_{2}, 30 \% \mathrm{~N}_{2}$ by volume (thus the designation CHN). Surrounding the fuel nozzle is a $250-\mathrm{mm}$ coflow nozzle that provides well-conditioned air to the flame. Additional air is provided through the annular space between the coflow and the HPCD walls for cooling. The baseline condition (CHN 01-01) is identical to the TNF chnA flame. Two series of flames are explored. In one series, the Reynolds number is kept constant at 16,700 for pressures up to 5 bar. In the other series, the bulk jet velocity is kept constant at $77.3 \mathrm{~m} / \mathrm{s}$ for pressures up to 5 bar. All flame conditions are listed in Table 1.

\subsection{Diagnostics}

The diagnostics setup is shown with the HPCD and CHN burner in Fig. 1. Images of each flame are recorded with a Canon EOS 7D DSLR with EF 28$135 \mathrm{~mm} \mathrm{f} / 3.5-5.6$ IS USM lens using shutter speeds between $1 / 50 \mathrm{~s}$ and $1 / 25 \mathrm{~s}$, an aperture of $\mathrm{f} / 3.5$ and ISO 100 . To adequately characterize and cover the entire flame, fifty images are captured at four different axial positions.

For the laser-induced fluorescence of OH, a dye laser (Sirah CREDO-DYE$\mathrm{N}$ ) is pumped by the second harmonic of a Nd:YAG laser (Edgewave IS200$2 \mathrm{~L}$ ). The dye laser produces a fundamental beam at $566 \mathrm{~nm}$ with Rhodamine $6 \mathrm{G}$. The frequency doubled beam is tuned to $\lambda=282.945 \mathrm{~nm}$ to excite the $\mathrm{OH}$ molecules using the $\mathrm{Q}_{1}(6)$ line of the $A^{2} \Sigma-X^{2} \Pi(1,0)$ transition. The operating condition of the laser is approximately $2.6 \mathrm{~W}$ at $10 \mathrm{kHz}$. A small fraction of the beam is directed into a power meter to monitor the shot-to-shot energy. The laser beam is expanded through a cylindrical lens and a spherical 
lens, creating a focused sheet. After it is expanded using a third cylindrical lens $(f=-50 \mathrm{~mm})$, this sheet is then passed through a UV fused silica window into the HPCD and through the center of the burner, where the beam has expanded to roughly $100 \mathrm{~mm}$ in height. A beam stop on the other side of the CHN burner prevents the beam from reflecting off the inside surface of the other window.

An intensified CMOS camera (LaVision HSS8/IRO) is used to acquire the fluorescence signal through another UV fused silica window at an angle of $90^{\circ}$. The signal is filtered through a high-transmission band-pass interference filter centered at $310 \mathrm{~nm}$. For each flame, a set of 3000 images are taken for analysis at two different stations, each covering about $70 \mathrm{~mm}$ of the flame, with an overlapping region of $10 \mathrm{~mm}$. For each set, the images are corrected by removing the average background noise and by normalizing for energy fluctuations of the Nd:YAG laser. A laminar flame is used to estimate laser sheet inhomogeneities and a correction based on these images is then applied to the images of the turbulent flames to produce the fully-processed results. After this, a smoothing operation is applied to remove pixelated features.

The corrected images are then used to generate a 2D flame front as follows. Each image is split along the centerline to form a left and right image, which are then analyzed separately. Edges of the $\mathrm{OH}$ layer are detected using a gradientbased Canny algorithm with unspecified threshold values [40,41]. This method uses strong and weak gradient thresholds, minimizing the effects of noise, and by not specifying the thresholds, the algorithm chooses them heuristically. Edges on the air (lean) side of the $\mathrm{OH}$ layer are eliminated, leaving only edges with relatively sharp gradients on the fuel (rich) side of the flame. These contours closely follow the reaction zone and are defined as the flame front.

\section{Results and Discussion}

The HPCD was used to successfully operate all nine flame conditions, showing that unpiloted, fully-attached, very high Reynolds number (up to 83,500) flames can be achieved if elevated pressures are possible.

\subsection{DSLR images and flame length}

Fifty DSLR camera images at four different axial locations have been averaged and stitched together to create a composite image of the full flame for all nine conditions. The resulting images are presented in Fig. 2 and Fig. 3 for the constant Re flame series and the constant $U_{j}$ series, respectively. The baseline case has a bluish base which fades to white and then has an orange tip. This trend is maintained for the constant velocity cases, whereas for the constant Reynolds number flames, the orange region moves upstream and occupies the entire flame at 4 and 5 bar.

The flame length is defined as the maximum height at which a flame is detected $50 \%$ of the time in the DSLR images. Flame lengths are plotted as 


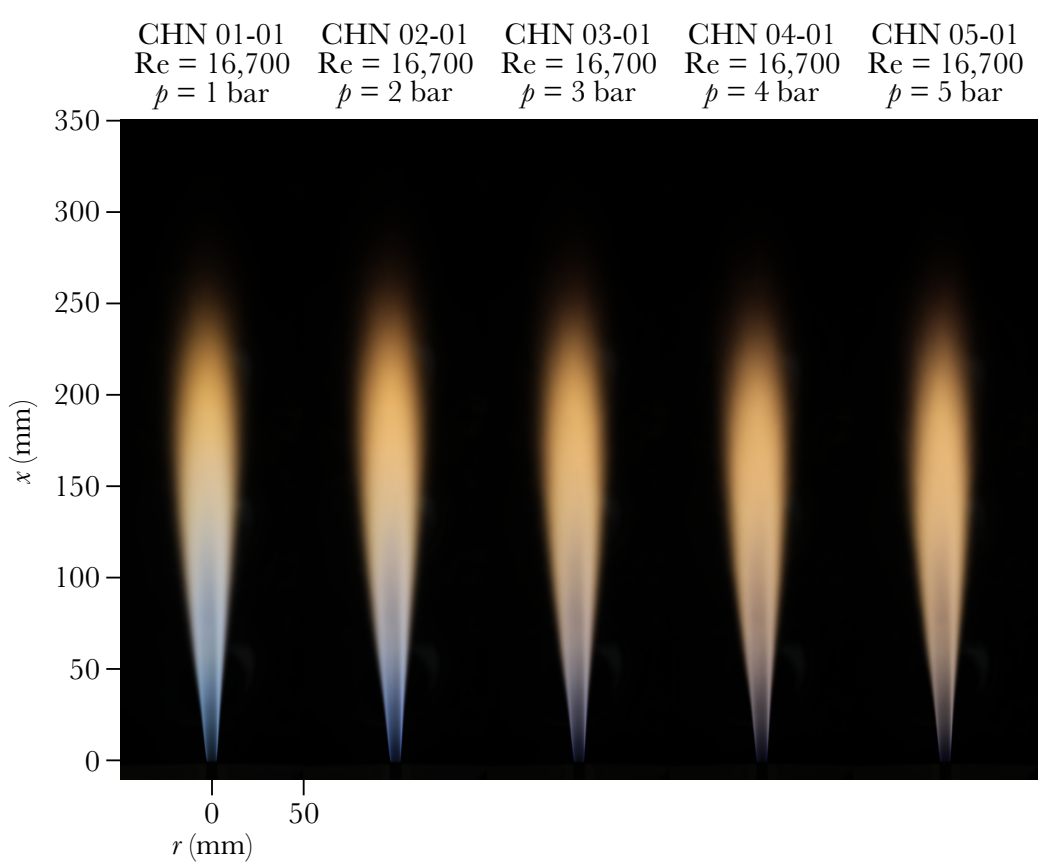

Fig. 2 Composite images of CHN flames in the constant Re series.

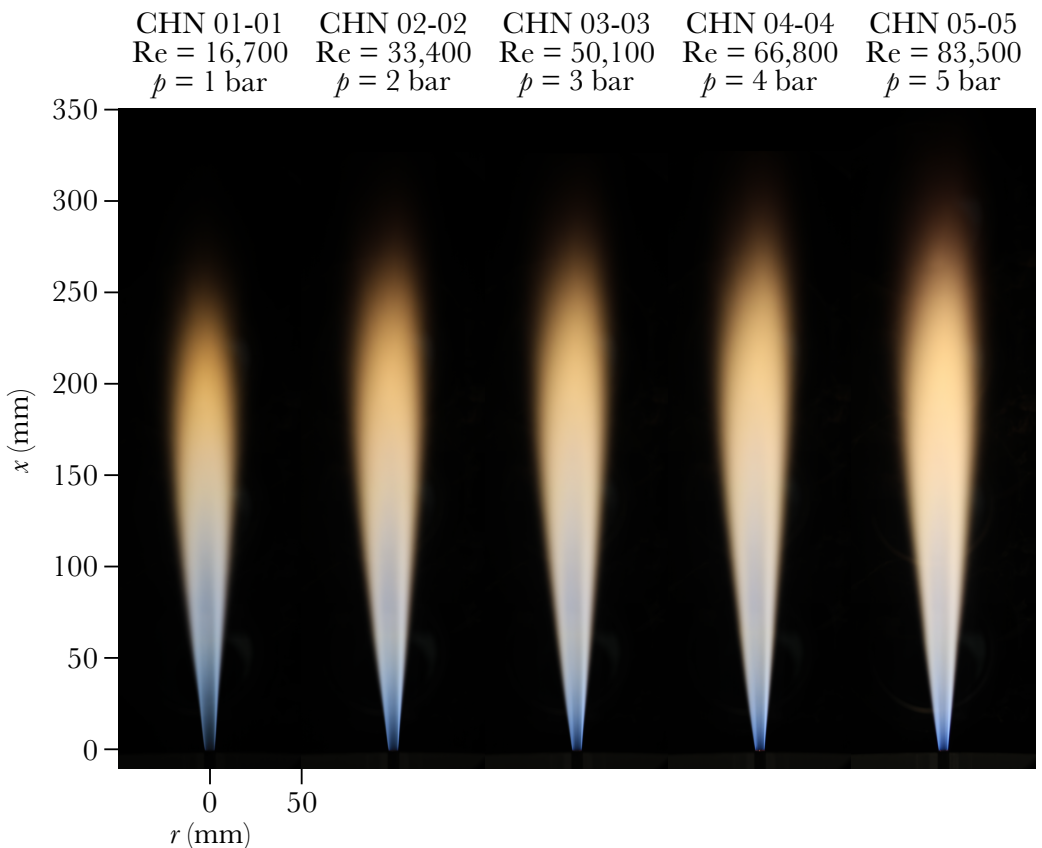

Fig. 3 Composite images of CHN flames in the constant $U_{j}$ series. 

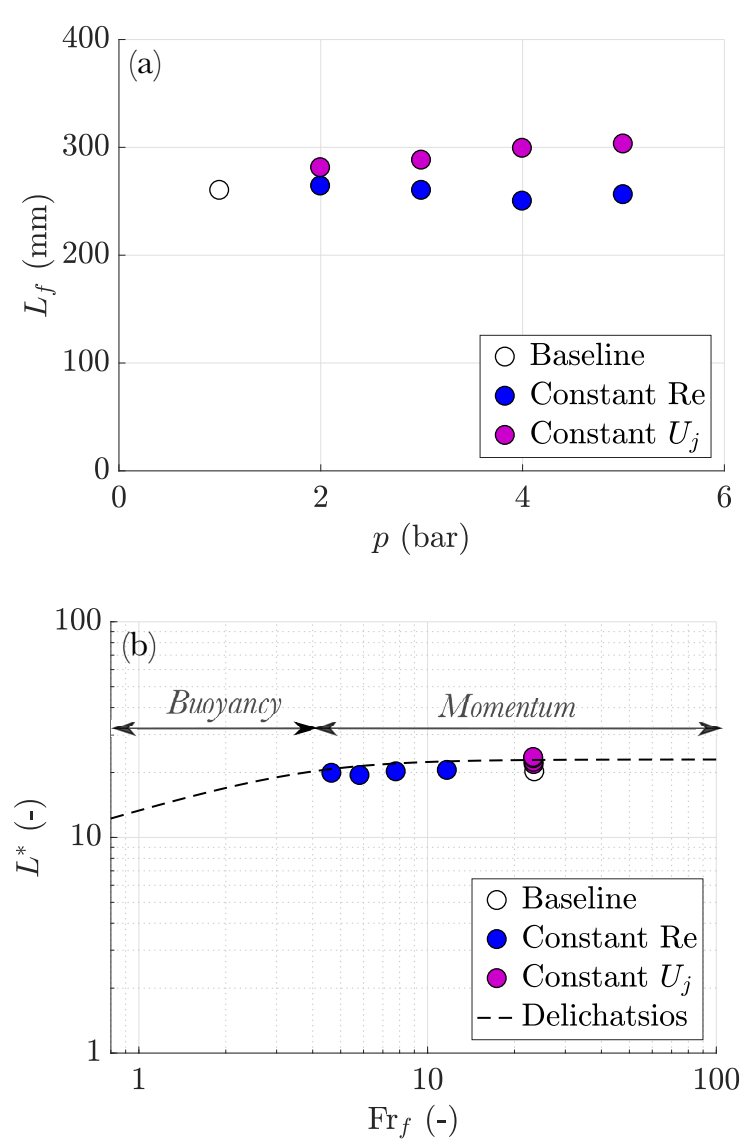

Fig. 4 Measured flame lengths: (a) as a function of pressure, and (b) non-dimensionalized and plotted against flame Froude number with the Delichatsios correlation curve.

a function of pressure in Fig. 4a. There is little change in length for constant Reynolds number flames, whereas the length increases gradually with increasing pressure in the constant velocity series, with the flame at 5 bar being roughly $10 \%$ longer than the baseline flame.

The non-dimensionalized flame lengths are plotted as a function of the flame Froude number according to the Delichatsios equations (1-3) in Fig. 4b. The Delichatsios correlation is plotted as a black dashed line. The constant Reynolds number points are almost in a straight line, with the Froude number decreasing as the pressure increases, due to the decreasing bulk jet velocity. The constant velocity points are practically indistinguishable, with $L^{*}$ increasing slightly as pressure increases. All of the data points lie very close to the Delichatsios curve, indicating excellent agreement with the existing correlation, which is based solely on results at atmospheric pressure. All of the constant velocity flames are clearly in the momentum-dominated regime, while 

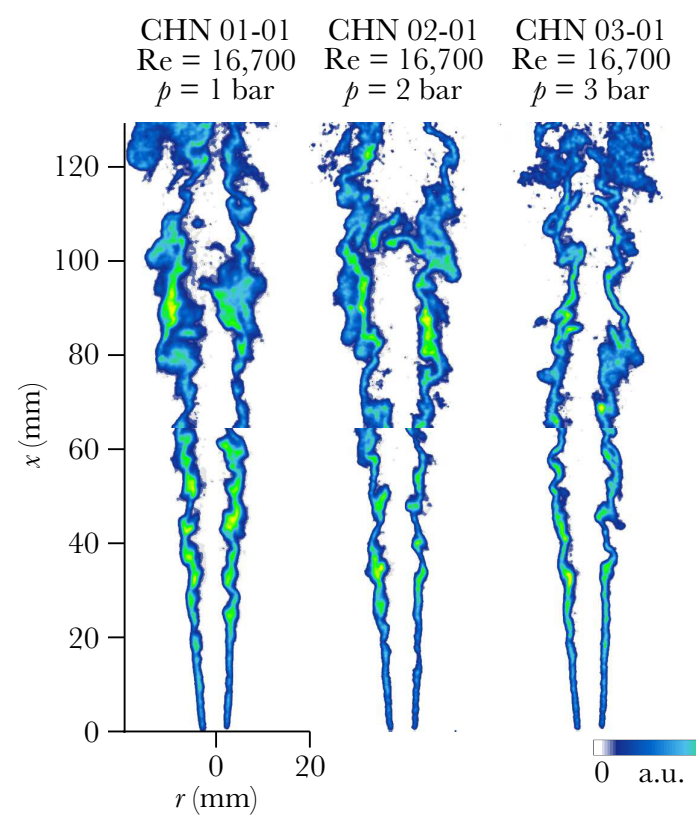

GHN 04-01

CHN 05-01 $p=3$ bar $p=4$ bar

$\mathrm{Re}=16,700$
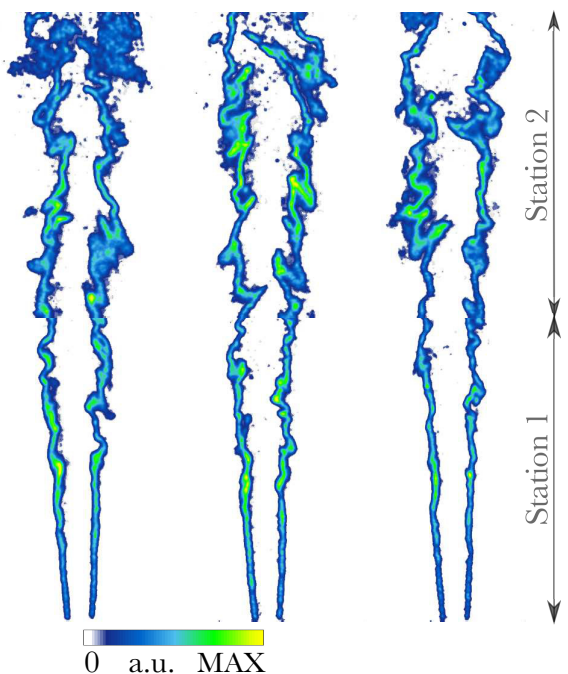

Fig. 5 Instantaneous OH-PLIF images of CHN flames in the constant Re series.

the constant Reynolds number flames at pressures of 4 and 5 bar are close to the buoyancy-momentum transition.

\subsection{Instantaneous OH-PLIF images}

Instantaneous OH-PLIF images at two different axial locations are shown for each flame in the constant Reynolds number series in Fig. 5 and for each flame in the constant bulk jet velocity series in Fig. 6 . The images at stations 1 and 2 are uncorrelated. The colormap for each image is normalized to the maximum value in that image, so intensities cannot be compared. It may be seen from the images that the intensity is usually greatest near the vertical center, indicating that, while the spatial correction dramatically improved the quality of the images, the correction was only partial. This, however, does not appreciably affect the following analysis.

In examining the constant Reynolds number images in Fig. 5, many of the trends noted in [34] and [26] may be observed. Each flame consists of thin filaments of $\mathrm{OH}$ which are connected by thicker zones. The $\mathrm{OH}$ layers tend to exhibit relatively large structures (compared to the width of the layer), which suggests they are distributed by moderately-sized eddies. In general, the layers increase in thickness and become more convoluted further downstream of the nozzle. It is also noted that the gradient on the fuel side of the layer tends to be steeper than on the lean side, a feature of $\mathrm{OH}$ profiles that has been noted previously [42]. The most striking feature of this set of images is the 

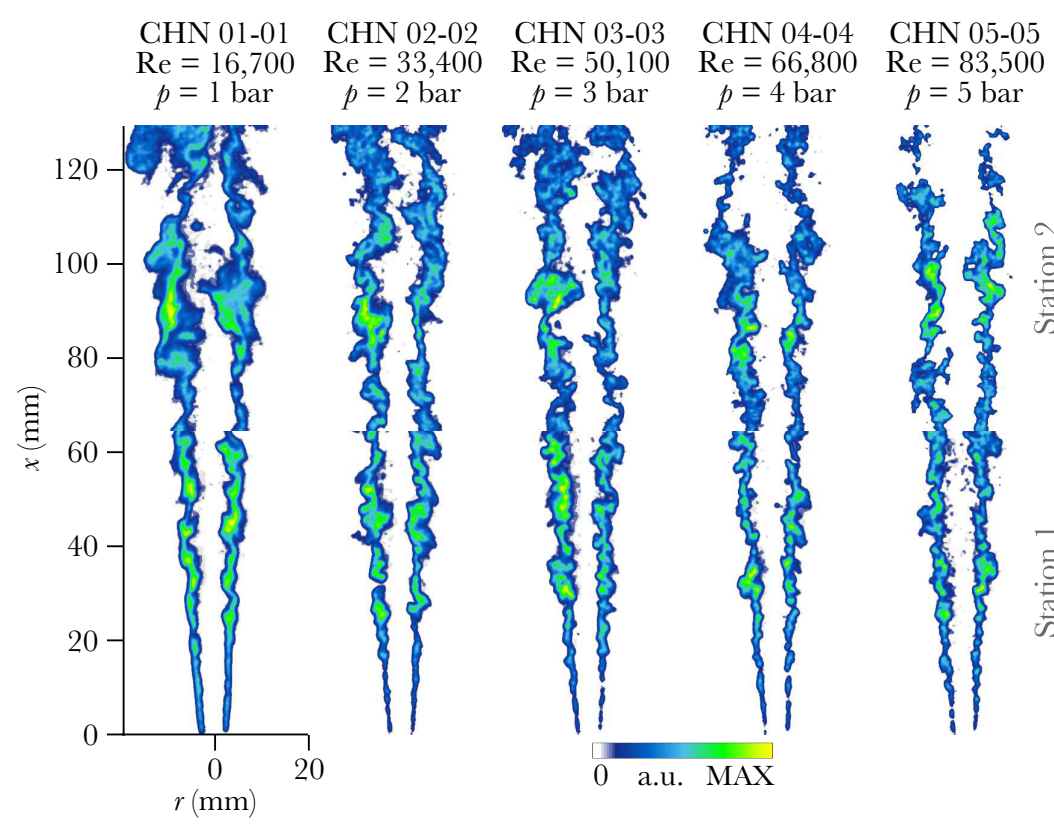

Fig. 6 Instantaneous OH-PLIF images of CHN flames in the constant $U_{j}$ series.

reduction in the width of the $\mathrm{OH}$ layer as pressure increases. Both simulations and experiments have confirmed that pressure reduces $\mathrm{OH}$ layer thickness by enhancing radical recombination rates [43].

The images from the constant velocity series in Fig. 6 are remarkably different than those in Fig. 5. The thin filaments are mostly absent, replaced by thickened blobs of $\mathrm{OH}$ joined by much shorter segments. Some large-scale structures remain, but the salient feature is the presence of highly corrugated layers, clearly influenced by small-scale turbulence. Furthermore, the fineness and degree of corrugation appears to increase as the Reynolds number (and pressure) increase. It is interesting to note that even the most extreme case $(\mathrm{Re}=83,500)$ exhibits very little local extinction.

\section{$3.3 \mathrm{OH}$ layer corrugation}

In order to quantify the corrugation of the OH-PLIF images, a flame front is extracted using the method described in Section 2.2. The flame front is a pixel-wide contour along the rich side of the $\mathrm{OH}$ layer. A mean flame front is calculated by taking the mean of all $\mathrm{OH}$ images for a given flame and using the same procedure to identify the rich-side contour of the $\mathrm{OH}$ layer. Then a corrugation factor may be defined for each image by taking the ratio of the length of the flame front in that image to the length of the mean flame front. The corrugation factor is a simple non-dimensional metric for quantifying the degree of corrugation of the flame front in any image. If a break in the $\mathrm{OH}$ layer 

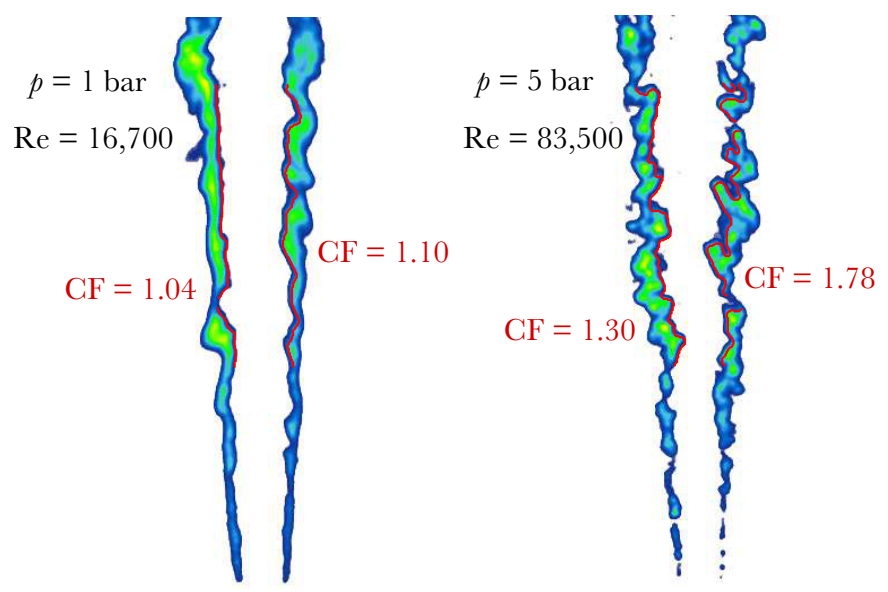

Fig. 7 Illustration of flame front contours (red lines) overlayed on $\mathrm{OH}$ fields, with left and right corrugation factors $(\mathrm{CF})$ labeled.

occurs, a representative length of the mean flame front is removed to avoid underestimating the corrugation factor. Two examples are given to illustrate the technique, in Fig. 7. Red lines representing the flame fronts are overlayed on the $\mathrm{OH}$ images. On the left is an image from a flame at a pressure of 1 bar and the lowest Reynolds number and on the right is an image from a flame at a pressure of 5 bar and the highest Reynolds number. Each flame front is labeled with the calculated corrugation factor. As expected, the low Reynolds number image shows less corrugation and this is reflected in corrugation factors close to 1, whereas the high Reynolds number image reveals a finely convoluted flame structure and thus has significantly higher corrugation factors.

Corrugation factors are computed for each of the flames over different ranges of $x / D$. In doing so, it is possible to assess the effects of pressure, Reynolds number, and axial location on the corrugation (wrinkling) of a $2 \mathrm{D}$ slice of the $\mathrm{OH}$ layer. This is done for three axial locations: $5 \leq x / D \leq 10$, $10 \leq x / D \leq 15$, and $15 \leq x / D \leq 20$. Beyond $x / D>20$, this metric ceases to be useful due to excessive large-scale mixing.

Figure 8 shows the resulting probability density functions (PDFs) for the corrugation factors of each flame (roughly 6000 values per flame). The probabilities are grouped by constant Reynolds number (left column) and constant bulk jet velocity (right column). In considering the constant Reynolds number corrugation factors, it is apparent that the distributions change very little with pressure. This is true regardless of axial location in the flame. As the region of interest moves downstream, the $\mathrm{OH}$ layer becomes slightly more corrugated. For the $p=1$ bar case, the mean corrugation factor changes from 1.13 close to the nozzle, to 1.29 slightly further away, and finally to 1.43 in the region $15 \leq x / D \leq 20$. This progression is representative of all of the flames in the $\operatorname{Re}=16,700$ series. 

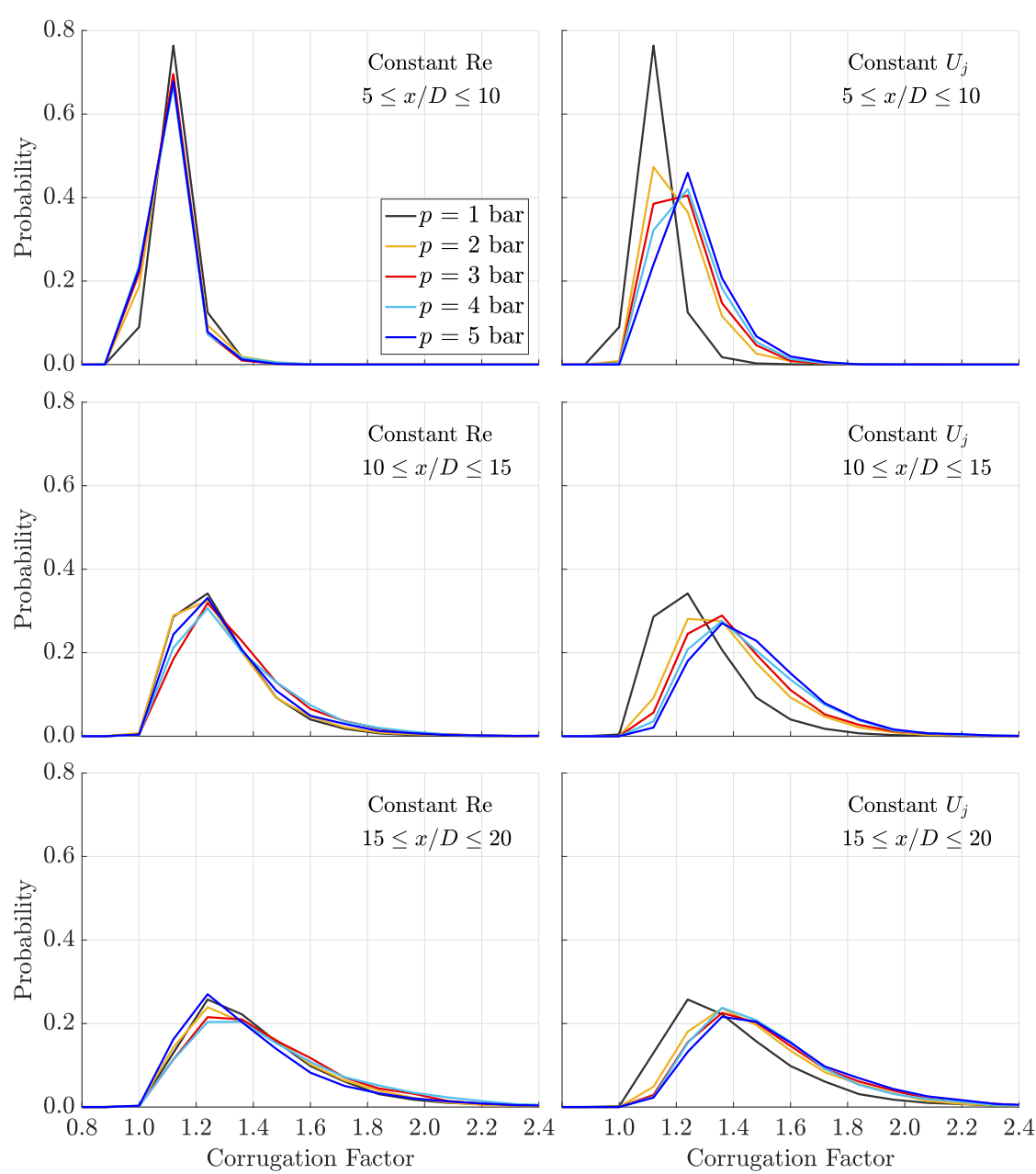

Fig. 8 Probability density functions of corrugation factors for each CHN flame in the constant Re series (left column) and the constant $U_{j}$ series (right column) over ranges of $x / D$ that are progressively further away from the nozzle.

In the constant velocity series, on the other hand, analysis reveals that the corrugation of the flame front changes considerably as the Reynolds number (and pressure) are increased. This was anticipated from the OH-PLIF images in Fig. 6. For instance, the $p=5$ bar, $\operatorname{Re}=16,700$ flame has a mean corrugation factor of 1.11 at $5 \leq x / D \leq 10$, whereas the $p=5$ bar, $\operatorname{Re}=83,500$ has a mean corrugation factor of 1.29. As with the constant Reynolds number series, the corrugation of the $\mathrm{OH}$ layer in the flames of the constant velocity series tends to increase as the distance away from the nozzle increases. However, the progression is slower, particularly for the high Reynolds number flames, and at $15 \leq x / D \leq 20$, there is much less distinction between the PDFs in the constant velocity series than in the constant Reynolds number series. At this 
location, there is little distinction with regard to Reynolds number at all: the $p=3$ bar, $\operatorname{Re}=16,700$ flame has a mean corrugation factor of 1.48 and the $p$ $=3$ bar, $\operatorname{Re}=50,100$ flame has a mean corrugation factor of 1.57 . The PDF of the lowest Reynolds number case, however, tends to be distinct from the other PDFs in the constant velocity series at each of the axial locations. This might be an indication that the $p=1$ bar, $\operatorname{Re}=16,700$ flame is not quite fully turbulent, but is instead transitional.

The trends in corrugation factor PDFs describe well some phenomena of turbulent nonpremixed flames that have been observed elsewhere. $\mathrm{OH}$ layer corrugation is strongly affected by the small-scale turbulence, which increases with the Reynolds number [26]. At the two lowest axial positions, the mean corrugation factor monotonically increases from the lowest Reynolds number case to the highest Reynolds number case, indicating that the corrugation factor, as defined here, is a useful analytical tool in that it provides quantitative data from mostly qualitative OH-PLIF images. Furthermore, corrugation factors near a value of 1 (where 1 is representative of a laminar flame) are indicative of laminarization in the near field of the jet as a result of increases in kinematic viscosity resulting in a reduction of the local Reynolds number [44]. Pressure appears to have little influence on flame corrugation if the Reynolds number is held constant.

There are inevitably some limitations to the analysis provided here. The first is that this analysis relies entirely on OH-PLIF images. A better estimation of the flame structure could be obtained with an additional spatiallyresolved scalar, such $\mathrm{CH}_{2} \mathrm{O}$ or $\mathrm{CO}$ [37], or temperature [45]. However, experiments show that the fuel side contour of the $\mathrm{OH}$ layer is a reasonable approximation of the flame contour and, in the near field of turbulent nonpremixed jet flames, the fuel side of the $\mathrm{OH}$ field is readily identified even without direct measurement of fuel concentration. Turbulence is an inherently three-dimensional phenomenon in jet flames, and simulations coupled with experiments have shown that extinction and re-ignition, for instance, are influenced by 3D effects [46]. For the purposes of this analysis, it should be recognized that the corrugation of a line in a $2 \mathrm{D}$ plane is only a rough approximation of the wrinkling of a surface in three dimensions. Lastly, it is possible that the measured corrugation of the $\mathrm{OH}$ layer is influenced by limitations in the spatial resolution of the OH-PLIF technique. For the purposes of this study, the intent was to demonstrate the ability to investigate jet flames at conditions relevant to practical combustion devices and to broadly characterize the behavior of such flames. Therefore, a large field of view was preferred over high spatial resolution. It is acknowledged that better statistical convergence of corrugation factors and enhanced differentiation of the corrugation factor PDFs as a function of Reynolds number may be achieved by low-speed, high-resolution, high-power OH-PLIF as opposed to the high-speed OH-PLIF utilized here. 


\section{Conclusions}

Nine flames that are variations of the chnA flame from the TNF Workshop have been explored in the high pressure combustion duct at KAUST. The chosen flames cover entirely new territory in the existing literature and are more relevant to the operating conditions of practical combustion devices than typical jet flame experiments, both in terms of pressure and Reynolds number. Analysis of DSLR images reveals that the flame length behavior is in agreement with the correlations offered by Delichatsios [31]. OH-PLIF images show an unbroken $\mathrm{OH}$ layer at 1 bar, which becomes thinner as pressure increases, and more corrugated as the Reynolds number increases. A corrugation factor is defined to quantify the degree of corrugation of the flame front in the OH-PLIF images. Probability density functions of the corrugation factors show that pressure has little influence on the flame front corrugation, whereas changes in Reynolds number have a dramatic effect.

Future work should focus on pushing the conditions to higher pressures and higher Reynolds numbers. Flame length measurements on higher-pressure, low Reynolds number flames will test the Delichatsios correlation in the buoyancydominant regime. OH-PLIF could be aided by higher resolution, especially at higher pressures and Reynolds numbers, in order to definitively resolve the flame front.

Acknowledgements The research reported in this publication was supported by funding from King Abdullah University of Science and Technology (KAUST).

\section{Compliance with Ethical Standards:}

Funding: This study was funded by King Abdullah University of Science and Technology (no grant number).

Conflict of Interest: The authors declare that they have no conflict of interest.

\section{References}

1. R. W. Bilger. Turbulent Jet Diffusion Flames. Prog. Energy Combust. Sci., 1:87-109, 1976.

2. L. Y. M. Gicquel, G. Staffelbach, and T. Poinsot. Large Eddy Simulations of gaseous flames in gas turbine combustion chambers. Prog. Energy Combust. Sci., 38:782-817, 2012 .

3. Joseph C. Oefelein, Robert W. Schefer, and Robert S. Barlow. Toward Validation of Large Eddy Simulation for Turbulent Combustion. AIAA J., 44(3):418-433, 2006.

4. K. N. C. Bray. The Challenge of Turbulent Combustion. Symp. (Int.) Combust. 26, pages $1-26,1996$.

5. R. W. Bilger, S. B. Pope, K. N. C. Bray, and J. F. Driscoll. Paradigms in turbulent combustion research. Proc. Combust. Inst. 30, pages 21-42, 2005.

6. H. Pitsch and H. Steiner. Large-eddy simulation of a turbulent piloted methane/air diffusion flame (Sandia flame D). Phys. Fluids, 12(10):2541-2554, 2000. 
7. Warren C. Strahle. Preface to "Evaluation of Data on Simple Turbulent Reacting Flows". Prog. Energy Combust. Sci., 12:253-255, 1986.

8. G. M. Faeth and G. S. Samuelsen. Fast Reaction Nonpremixed Combustion. Prog. Energy Combust. Sci., 12:305-372, 1986.

9. M. C. Drake and W. Kollmann. Slow Chemistry Nonpremixed Flows. Prog. Energy Combust. Sci., 12:373-392, 1986.

10. A. R. Masri, R. W. Dibble, and R. S. Barlow. The Structure of Turbulent Nonpremixed Flames Revealed by Raman-Rayleigh-LIF Measurements. Prog. Energy Combust. Sci., 22:307-362, 1996.

11. S. B. Pope. Computations of Turbulent Combustion: Progress and Challenges. Symp. (Int.) Combust. 23, pages 591-612, 1990.

12. TNF Workshop - International Workshop on Measurement and Computation of Turbulent Nonpremixed Flames. https://tnfworkshop.org/.

13. R. S. Barlow and C. D. Carter. Relationships among Nitric Oxide, Temperature, and Mixture Fraction in Hydrogen Jet Flames. Combust. Flame, 104:288-299, 1996.

14. R. S. Barlow, G. J. Fiechtner, C. D. Carter, and J.-Y. Chen. Experiments on the Scalar Structure of Turbulent $\mathrm{CO} / \mathrm{H}_{2} / \mathrm{N}_{2}$ Jet Flames. Combust. Flame, 120:549-569, 2000.

15. W. Meier, R. S. Barlow, Y.-L. Chen, and J.-Y. Chen. Raman/Rayleigh/LIF Measurements in a Turbulent $\mathrm{CH}_{4} / \mathrm{H}_{2} / \mathrm{N}_{2}$ Jet Diffusion Flame: Experimental Techniques and Turbulence-Chemistry Interaction. Combust. Flame, 123:326-343, 2000.

16. Brent A. Rankin, Gaetano Magnotti, Robert S. Barlow, and Jay P. Gore. Radiation intensity imaging measurements of methane and dimethyl ether turbulent nonpremixed and partially premixed jet flames. Combust. Flame, 161:2849-2859, 2014.

17. J. H. Frank, R. S. Barlow, and C. Lundquist. Radiation and Nitric Oxide Formation in Turbulent Non-Premixed Jet Flames. Proc. Combust. Inst. 28, pages 447-454, 2000.

18. B. B. Dally, D. F. Fletcher, and A. R. Masri. Flow and mixing fields of turbulent bluff-body jets and flames. Combust. Theory Model., 2:193-219, 1998.

19. Thabo Stahler, Dirk Geyer, Gaetano Magnotti, Philipp Trunk, Matthew J. Dunn, Robert S. Barlow, and Andreas Dreizler. Multiple conditioned analysis of the turbulent stratified flame A. Proc. Combust. Inst. 36, pages 1947-1955, 2017.

20. Mark S. Sweeney, Simone Hochgreb, Matthew J. Dunn, and Robert S. Barlow. The structure of turbulent stratified and premixed methane/air flames II: Swirling flows. Combust. Flame, 159:2912-2929, 2012.

21. R. S. Barlow, S. Meares, G. Magnotti, H. Cutcher, and A. R. Masri. Local extinction and near-field structure in piloted turbulent $\mathrm{CH}_{4} /$ air jet flames with inhomogeneous inlets. Combust. Flame, 162:3516-3540, 2015.

22. W. L. Flower. An investigation of soot formation in axisymmetric turbulent diffusion flames at elevated pressure. Symp. (Int.) Combust. 22, pages 425-435, 1988.

23. K. J. Young, C. D. Stewart, and J. B. Moss. Soot formation in turbulent nonpremixed kerosine-air flames burning at elevated pressure: experimental measurement. Symp. (Int.) Combust. 25, pages 609-617, 1994.

24. B. A. Fischer and J. B. Moss. The influence of pressure on soot production and radiation in turbulent kerosine spray flames. Combust. Sci. Technol., 138:43-61, 1998.

25. S. J. Brookes and J. B. Moss. Measurements of soot production and thermal radiation from confined turbulent jet diffusion flames of methane. Combust. Flame, 116:49-61, 1999.

26. N. T. Clemens, P. H. Paul, and M. G. Mungal. The Structure of OH Fields in High Reynolds Number Turbulent Jet Diffusion Flames. Combust. Sci. Technol., 129:165184, 1997.

27. Robert S. Barlow. Laser diagnostics and their interplay with computations to understand turbulent combustion. Proc. Combust. Inst. 31, pages 49-75, 2007.

28. W. R. Hawthorne, D. S. Weddell, and H. C. Hottel. Mixing and Combustion in Turbulent Gas Jets. In 3rd Symp. Combust. Flame Explos. Phenom., pages 266-288, 1949.

29. H. A. Becker and D. Liang. Visible Length of Vertical Free Turbulent Diffusion Flames. Combust. Flame, 32:115-137, 1978.

30. Gautam T. Kalghatgi. Lift-off Heights and Visible Lengths of Vertical Turbulent Jet Diffusion Flames in Still Air. Combust. Sci. Technol., 41:17-29, 1984.

31. M. A. Delichatsios. Transition from Momentum to Buoyancy-Controlled Turbulent Jet Diffusion Flames and Flame Height Relationships. Combust. Flame, 92:349-364, 1993. 
32. Jeongjae Hwang, Kitae Sohn, Nicolas Bouvet, and Youngbin Yoon. NOx Scaling of Syngas $\mathrm{H}_{2} / \mathrm{CO}$ Turbulent Non-Premixed Jet Flames. Combust. Sci. Technol., 185(12):1715-1734, 2013.

33. Longhua Hu, Qiang Wang, Michael Delichatsios, Fei Tang, Xiaochun Zhang, and Shouxiang Lu. Flame height and lift-off of turbulent buoyant jet diffusion flames in a reduced pressure atmosphere. Fuel, 109:234-240, 2013.

34. Jerry M. Seitzman, Aziz Üngüt, Phillip H. Paul, and Ronald K. Hanson. Imaging and characterization of $\mathrm{OH}$ structures in a turbulent nonpremixed flame. Symp. (Int.) Combust. 23, pages 637-644, 1990.

35. P. S. Kothnur, M. S. Tsurikov, N. T. Clemens, J. M. Donbar, and Campbell D. Carter. Planar Imaging of $\mathrm{CH}, \mathrm{OH}$, and Velocity in Turbulent Non-Premixed Jet Flames. Proc. Combust. Inst. 29, pages 1921-1927, 2002.

36. Robert L. Gordon, Assaad R. Masri, and Epaminondas Mastorakos. Heat release rate as represented by $[\mathrm{OH}] \times\left[\mathrm{CH}_{2} \mathrm{O}\right]$ and its role in autoignition. Combust. Theory Model., 13(4):645-670, 2009.

37. Cheng Chi, Gábor Janiga, Abouelmagd Abdelsamie, Katharina Zähringer, Tamás Turányi, and Dominique Thévenin. DNS Study of the Optimal Chemical Markers for Heat Release in Syngas Flames. Flow, Turbul. Combust., 98:1117-1132, 2017.

38. Wesley R. Boyette, Ayman M. Elbaz, Thibault F. Guiberti, and William L. Roberts. Experimental investigation of the near field in sooting turbulent nonpremixed flames at elevated pressures. Exp. Therm. Fluid Sci., 105:332-341, 2019.

39. TNF Workshop - $\mathrm{CO} / \mathrm{H} 2 / \mathrm{N} 2$ Jet Flames. https://tnfworkshop.org/dataarchives/simplejet/sandchn/.

40. John Canny. A Computational Approach to Edge Detection. IEEE Trans. Pattern Anal. Mach. Intell., 8(6):679-698, 1986.

41. Alan E. Bayley, Yannis Hardalupas, and Alex M. K. P. Taylor. Local curvature measurements of a lean, partially premixed swirl-stabilised flame. Exp. Fluids, 52:963-983, 2012.

42. Bruno Coriton, Masoomeh Zendehdel, Satoshi Ukai, Andreas Kronenburg, Oliver T. Stein, Seong Kyun Im, Mirko Gamba, and Jonathan H. Frank. Imaging measurements and LES-CMC modeling of a partially-premixed turbulent dimethyl ether/air jet flame. Proc. Combust. Inst. 35, pages 1251-1258, 2015.

43. A. Matynia, J. Molet, C. Roche, M. Idir, S. de Persis, and L. Pillier. Measurement of $\mathrm{OH}$ concentration profiles by laser diagnostics and modeling in high-pressure counterflow premixed methane/air and biogas/air flames. Combust. Flame, 159(11):3300-3311, 2012

44. T. Takagi, H. Shin, and A. Ishio. Local laminarization in turbulent diffusion flames. Combust. Flame, 37(2):163-170, 1980.

45. S. A. Kaiser and J. H. Frank. Spatial scales of extinction and dissipation in the near field of non-premixed turbulent jet flames. Proc. Combust. Inst. 32, pages 1639-1646, 2009.

46. Vinayaka N. Prasad, Mrinal Juddoo, Assaad R. Masri, William P. Jones, and Kai H. Luo. Investigation of extinction and re-ignition in piloted turbulent non-premixed methaneair flames using LES and high-speed OH-LIF. Combust. Theory Model., $17(3): 483-503,2013$. 